\title{
Study on the Change Rule of Soil Water in Land of Different Use Types in Taihang Mountain Area
}

\author{
Guangying Zhang \\ Baoding Soil and Water Conservation Experimental Station, Baoding, Hebe 074200, China
}

\begin{abstract}
This paper first studies the vertical structure and soil physical properties of Songlin Plot and Huangshan Plot in Chongling Small Watershed. Then, based on a series of field experiments, this paper obtains the basic parameters and infiltration characteristics of soil water movement in two runoff Plots with different land use types. After that, this paper analyzes the seasonal variation, vertical spatial change and the response to precipitation of land with different use types based on the data monitored in the runoff Plots under natural rainfall conditions. The result shows that the changes of soil water at different depths of Songlin Plot and Huangshan Plot are basically the same and that the soil water supply is completely controlled by precipitation. The water storage capacity of Songlin Plot is stronger, while the soil moisture variation of Huangpo Plot is higher, which indicates that Songlin Plot is more stable in terms of soil moisture content and stronger in self-adjustment.
\end{abstract}

\section{Introduction}

The distribution and storage of forest soil moisture in the basin and its transmission and movement in the soil are important links affecting the flow and distribution mechanism of forest watershed. The study on the distribution and movement law of forest soil moisture has been a major concern of hydrologists. In a sense, the impact of forest vegetation on the hydrological process is also the relationship between water storage capacity and storm water containment in the forest-soil system, so the regulation of forest vegetation on the hydrological process is actually realized through the interception of rainfall by the forest and the soil. ${ }^{[1]}$.

In order to study the change rule of soil water in the land of different use types, this paper first explores the characteristics of vertical structure and soil of the typical artificial slope runoff plot, and then analyzes the soil moisture dynamics under the natural rainfall condition.

\section{Overview of the test area and the observation project}

\subsection{Overview of the test area}

The Chongling Small Watershed is located in the gneiss hilly area of in the Yixian County of Hebei Province at the northern end of the Taihang Mountains $\left(115^{\circ} 21^{\prime}\right.$ east longitude and $39^{\circ} 23^{\prime}$ north latitude). Its elevation is about $90 \mathrm{~m}$, and the terrain slope is about $12^{\circ} \mathrm{C}$. The area belongs to the temperate continental monsoon climate, with the average annual precipitation of $560 \mathrm{~mm}$, the annual average temperature of $11.6{ }^{\circ} \mathrm{C}$, the annual average evaporation of $1906 \mathrm{~mm}(\Phi 20 \mathrm{~cm}$ evaporating dish), and the frost-free period of about $210 \mathrm{~d}$. In terms of the outcrop in the study area, the limestone and marble are mostly in the northwest, the purplish red conglomerate is in the southeast, the granitic gneiss is in the middle, and the Quaternary sediment is in the valley (the main components are sand, clay, loess and gravel). Field survey shows that the soil layer is generally thin with the depth of $5-30 \mathrm{~cm}$. The soil is mostly composed of sandy loam, and the loess, and is often mixed with a large amount of gravel. The lower part of the soil is a conglomerate weathering layer, with broken rock mass and complex and variable cracks. Vegetation mainly includes plantation such as pinus tabulaeformis, biota orientalis, and robinia pseudoacacia, small shrubs such as vitex negundovar, and ziziphus jujube var. spinosa, and herbaceous plots such as carex humilis, carex lanceolata, and bothriochloa ischaemum ${ }^{[2]}$. The study area has the typical natural conditions in the Taihang Mountains.

\subsection{Observation Project}

Since 1959, Soil and Water Conservation Experiment Station of Baoding City has been carrying out artificial observations of rainfall, runoff, sediment, and soil water in the Chongling Small Watershed. This paper selects Songlin Plot and Huangpo Plot for soil water observation, and installs a vacuum gauge at different depths of the two Plots for water potential observation.

Songlin Plot has a gradient of $12^{\circ}$, a slope length of $15 \mathrm{~m}$, a slope width of $5 \mathrm{~m}$, and a slope direction of 270 The Plot implements cave-like soil preparation and plants

"Corresponding Author: Guangying Zhang; email: 587378168@qq.com; 
Chinese pines.

Huangpo Plot has a gradient of $14^{\circ}$, a slope length of $15 \mathrm{~m}$, a slope width of $5 \mathrm{~m}$, and a slope of 270 . The Plot is a natural slope, planted with vitex and jujube.

The precipitation data uses the observation data of the meteorological field next to the two Plots. The meteorological field is equipped with a tipping-bucket self-metering rain gauge for precipitation observation.

\section{Result and analysis}

\subsection{Soil physical properties}

The physical properties of soil are an important manifestation of soil water holding capacity. Generally speaking, the smaller the unit weight of the soil, the larger the porosity and the greater the water holding capacity of the soil. From the perspective of the water retention capacity, the moisture in the capillary pores can usually be kept in the soil for a long time, which is mainly used for root absorption and soil evaporation. The water outside the capillary pores can be drained in time, which is more conducive to soil water infiltration ${ }^{[3]}$.
Understanding the physical properties of soil is the basis and premise for studying the movement of water in soil. Changes in the texture and physical properties of the soil directly affect its hydraulic conductivity, which is regarded as the mechanism for the forest to regulate water transport in the hydrological cycle of the basin ${ }^{[4]}$.

In order to further understand the vertical structure and soil physical properties of Songlin Plot and Huangpo Plot, this paper selects two areas around the Plots for artificial excavation and earth borrowing, and makes a detailed observation record of the vertical profile characteristics of the slope during excavation.

Figure 1 is a vertical cross-sectional photograph of the Songlin runoff Plot and Huangpo runoff Plot. The upper $20 \mathrm{~cm}$ of Songlin Plot is dark brown soil layer, and its lower part is a relatively uniform loess layer mixed with gravels. The roots are mainly distributed within $0 \sim 20 \mathrm{~cm}$ layer while some thicker roots are below $20 \mathrm{~cm}$. The $0 \sim 5 \mathrm{~cm}$ layer of Huangpo Plot is the dark-brown soil layer, and the $5 \sim 30 \mathrm{~cm}$ layer is mixed with a large amount of gravels, and the $30+\mathrm{cm}$ layer is the rock weathering layer. The plant roots are mostly distributed in the $30+\mathrm{cm}$ layer.

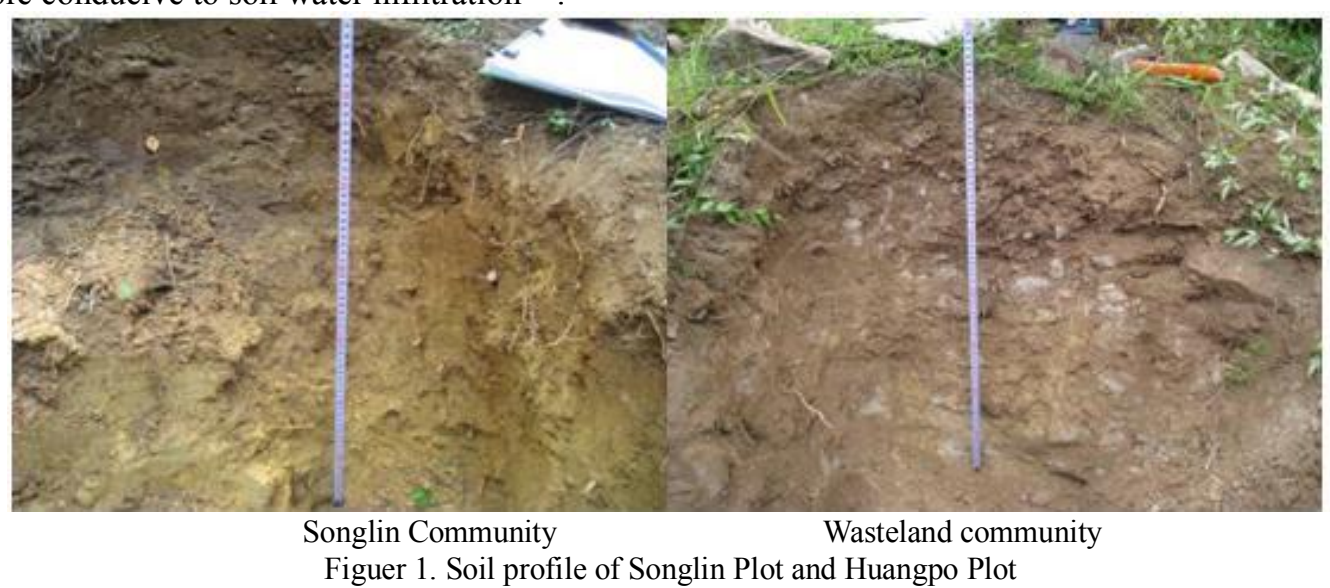

The analysis of physical characteristics of the soil in Songlin Plot and Huangpo Plot shows that the unit weight increases with the increase of depth from top to bottom. Due to the presence of gravel in the soil, the curve fluctuates to some extent. The saturated water content and the field water holding capacity slowly decreases.

Table 1 Physical properties of soil in the runoff plot

\begin{tabular}{lllllll}
\hline Type & Soil depthcm & $\begin{array}{l}\text { Bulk } \\
\text { weight } \\
\left(\mathrm{g} / \mathrm{cm}^{3}\right)\end{array}$ & $\begin{array}{l}\text { Saturated } \\
\text { moisture } \\
/ \%\end{array}$ & $\begin{array}{l}\text { Field } \\
\text { moisture } \\
\text { capacity } / \%\end{array}$ & $\begin{array}{l}\text { Porosity } \\
/ \%\end{array}$ & $\begin{array}{l}\text { Capillaw } \\
\text { pore } / \%\end{array}$ \\
\hline \multirow{2}{*}{$\begin{array}{l}\text { Songlin } \\
\text { Community }\end{array}$} & $0-5$ & 1.39 & 25.87 & 18.93 & 48.08 & 26.37 \\
& $5-10$ & 1.40 & 30.25 & 20.81 & 47.75 & 29.06 \\
& $10-15$ & 1.31 & 33.69 & 27.50 & 50.72 & 36.04 \\
& $15-20$ & 1.32 & 32.22 & 25.36 & 50.39 & 33.42 \\
& $20-25$ & 1.38 & 30.68 & 24.32 & 48.41 & 33.46 \\
& $30-35$ & 1.47 & 23.30 & 20.12 & 45.44 & 29.54 \\
& $40-45$ & 1.66 & 24.37 & 21.55 & 39.18 & 35.68 \\
& $50-55$ & 1.82 & 26.71 & 24.41 & & 44.50 \\
& $60-65$ & 1.84 & 21.08 & 19.16 & & 35.20 \\
\hline $0-5$ & 1.09 & 44.53 & 30.11 & 57.88 & 32.91
\end{tabular}




\begin{tabular}{lllllll}
$\begin{array}{l}\text { Wasteland } \\
\text { community }\end{array}$ & $5--10$ & 1.26 & 44.83 & 30.75 & 52.37 & 38.88 \\
& $10-15$ & 1.33 & 33.01 & 22.99 & 50.06 & 30.64 \\
& $20-25$ & 1.36 & 28.79 & 21.01 & 49.07 & 28.62 \\
& $30-35$ & 1.43 & 30.58 & 23.02 & 46.76 & 32.89 \\
& $40-45$ & 1.49 & 25.66 & 23.50 & 44.79 & 34.97 \\
& $50-55$ & 1.45 & 26.22 & 21.16 & 46.10 & 30.74 \\
& $60-65$ & 1.53 & 20.12 & 15.88 & 43.47 & 24.30 \\
\hline
\end{tabular}

\subsection{Dynamic characteristics of soil water}

From Figure 2 (the dynamic change of daily soil water content at different depths in different slopes of Songlin runoff plot and Huangpo runoff plot in 2005-2008), it can be seen that the trend of soil water changes at different depths is basically the same and that the supply of soil water is completely controlled by precipitation despite the plots and the reaches. In March and April when the precipitation is scarce, the soil water content is small, and the temperature is low. The vegetation just begins to

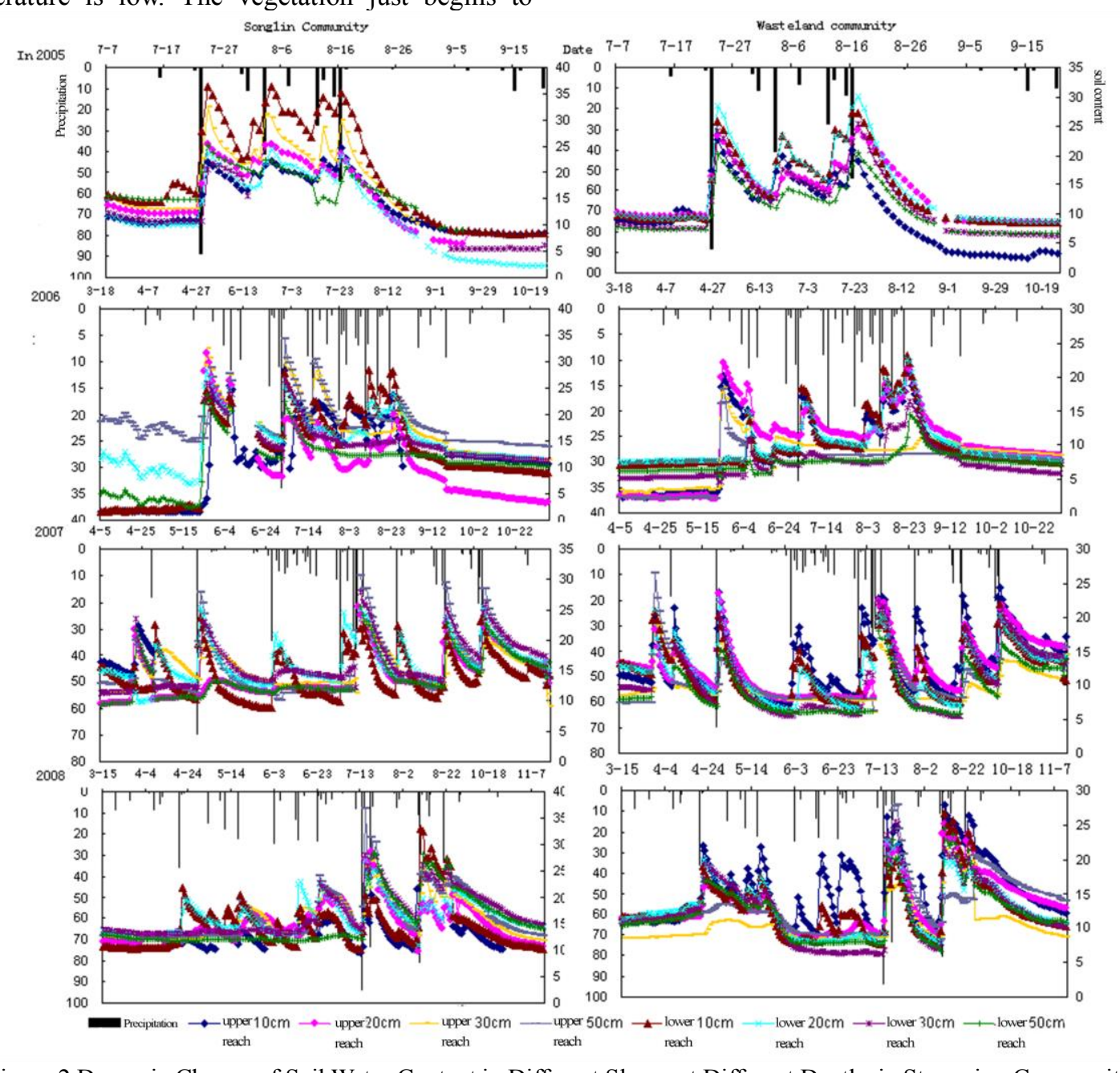

Figure 2 Dynamic Change of Soil Water Content in Different Slopes at Different Depths in Streaming Community

From Figure 3, we can see that the seasonal variation trends of soil water content in Songlin Plot and Huangpo Plot are basically the same. However, their soil water contents are different due to different vegetation. During

the study period, almost all monthly average soil water content values of Songlin Plot is greater than those of Huangpo Plot. develop, and the evapotranspiration is not obvious, so the soil water content is relatively stable ${ }^{[5]}$. As the flood season starts, the soil water is recharged greatly. But as the temperature rises, the vegetation begins to grow rapidly, during which the dissipation is also very fast. The process line fluctuates greatly, and the soil water content fluctuates drastically. Usually, the soil water content reaches the maximum of the whole year in July and August and slowly declines after October due to the reduction of precipitation. 


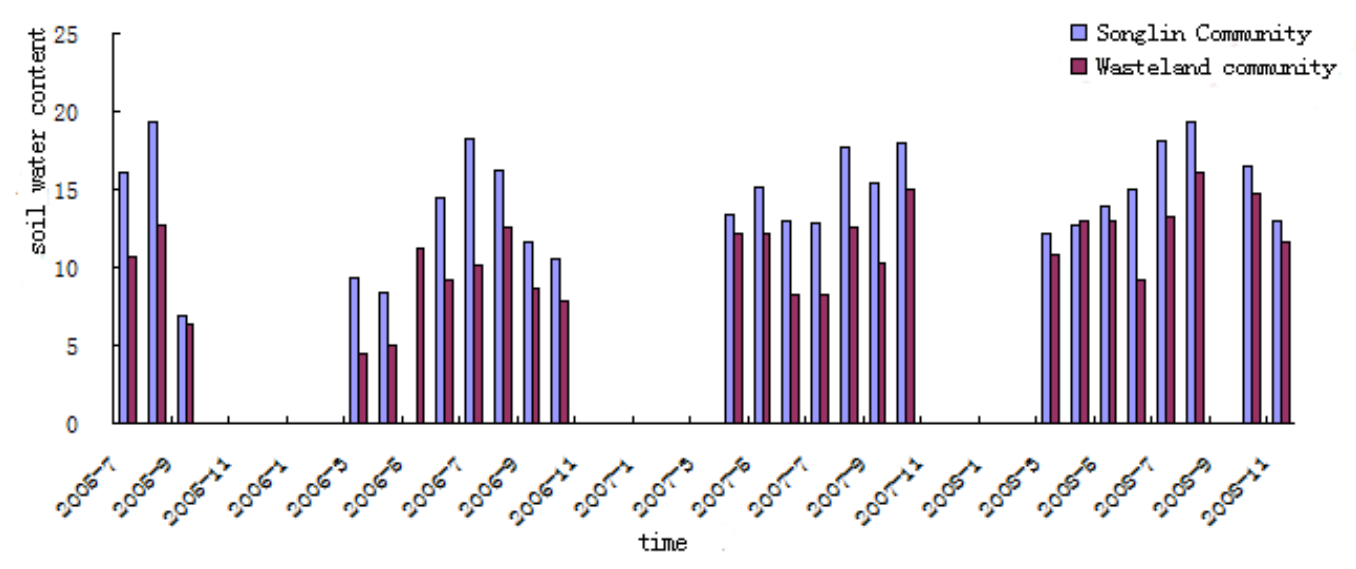

Figure 3 Seasonal variation of soil moisture content in runoff area

\subsection{Response of soil water to precipitation}

The analysis of response of the soil water to precipitation from July to September, 2005 shows that the soil moisture contents of the $10 \mathrm{~cm}$ and $20 \mathrm{~cm}$ layers respond very quickly to rainfall, and the daily precipitation exceeding $15 \mathrm{~mm}$ can lead to significant fluctuation of the water content of the two layers. As rainfall recharge ends, the soil water content of the $20 \mathrm{~cm}$ layer often reaches the maximum. In addition, the soil moisture content of $20 \mathrm{~cm}$ layer at other times is also often the highest, indicating that the soil water of the slope is mainly stored within $20 \mathrm{~cm}$ layer.

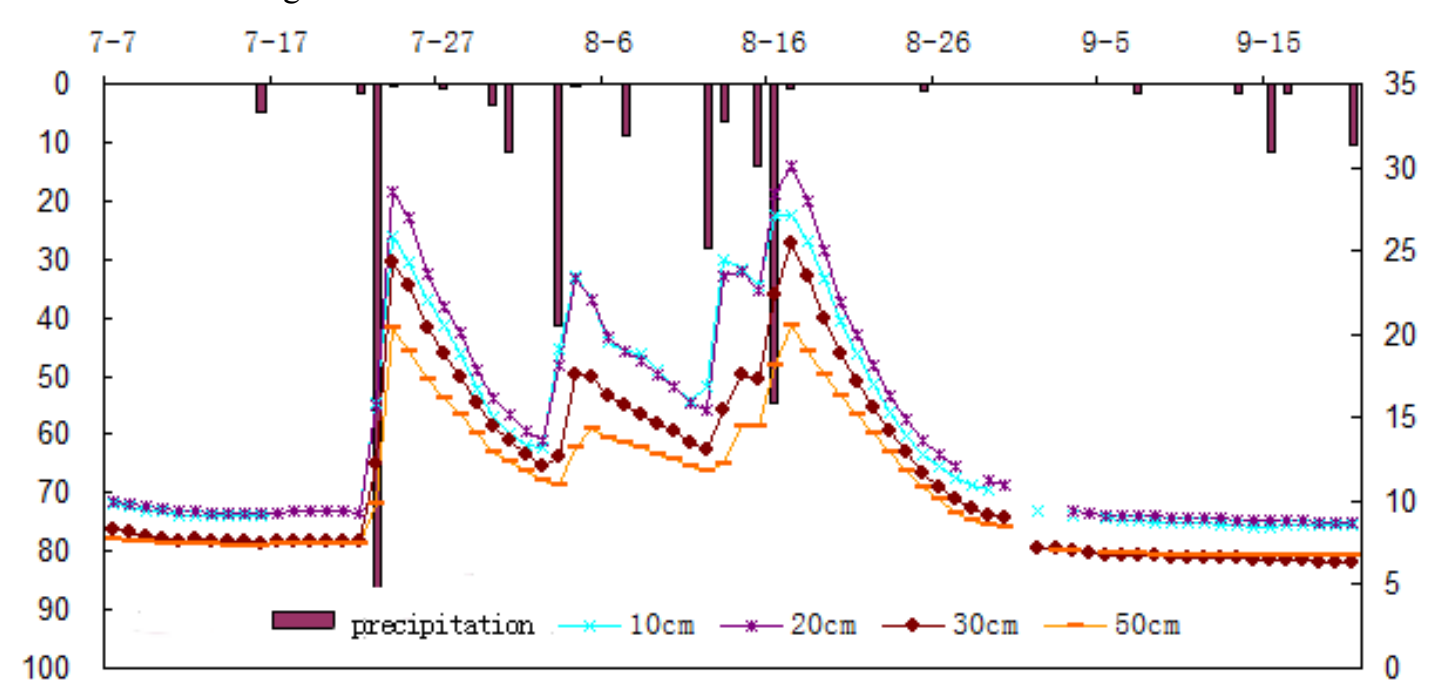

Figure 4 Response of soil water to precipitation in barren slopes

\subsection{Vertical distribution of soil moisture}

The vertical variation law of soil moisture is mainly dominated by the downward infiltration redistribution and the upward evaporation process, while these two processes are affected by various factors such as vegetation type, soil physical properties and climatic characteristics, which also change with time ${ }^{[6]}$. According to the soil moisture data from 2005 to 2008 (Fig. 5), it can be seen that the average soil water content of each layer of Songlin Plot is higher than that of Huangpo Plot, reflecting that the former one has a higher water storage capacity.

Within the $0-50 \mathrm{~cm}$ layer, the soil water content of both Plots increases first and then decreases with the increase of depth. That of Songlin Plot reaches the maximum at $30 \mathrm{~cm}$ and decreased at $50 \mathrm{~cm}$; that of Huangpo Plot reaches the maximum at $20 \mathrm{~cm}$, decreases at $30 \mathrm{~cm}$, and then increases again at $50 \mathrm{~cm}$. Shallow soil can easily receive precipitation infiltration, but it evaporate strongly. As the depth increases, evaporation rapidly reduces, and the soil water content is increased. As the depth continues to increase, due to the decrease of precipitation infiltration and water absorption of the roots and the reduction of the soil water content, a high water content inflection point is formed. The inflection point of Songlin Plot is larger than that of Huangpo Plot, indicating that the aquifer thickness in the former is greater than that in the latter. Due to the infiltration reduction from the upper soil layer, a low water inflection point appears at the $30 \mathrm{~cm}$ in Huangpo Plot.

The variation coefficient of soil moisture reflects the layer with active soil moisture. It can be seen that the variation coefficient of soil moisture of the two Plots fluctuates with depth, with an overall decreasing trend. In the surface layer and the deeper $50 \mathrm{~cm}$ layer, the difference is not distinct. In the middle layer, the soil moisture content of Huangpo Plot is higher than that of 
Songlin Plot, indicating that the latter has more stable



soil moisture content and is stronger in self-adjustment.

Figure 5 Distribution of Soil Moisture Measurement Data in Runoff Community

\section{Conclusion}

The soil layer of the slope in the study area is shallow and the soil structure has distinct features in the vertical direction. Through sampling and laboratory experiments, we obtain the basic physical characteristics such as unit weight of the soil, saturated water content, and field water holding capacity.

The variation trends of soil water at different depths of Songlin Plot and Huangpo Plot are basically the same, and the supply of soil water is completely controlled by precipitation. During the study period, the monthly average soil water content of Songlin Plot is always greater than that of Huangpo Plot, indicating that the water storage capacity of Songlin Plot is stronger. The soil water of the slope is mainly stored within $20 \mathrm{~cm}$ layer. The variability of soil moisture in Huangpo Plot is higher than that in Songlin Plot, indicating that Songlin Plot is more stable in terms of soil moisture content and stronger in self-adjustment.

\section{Acknowledgements}

The study was financially supported by the Hebei Provincial Water Resources Science and Technology Project (Grant No. 2018-63).

\section{Reference}

1. Liu Qingbai, Liu Mingguo, Wang Yutao et al. Comparison of soil water properties and water holding capacity of different forest types[J]. Arid Zone Research,2011,05.

2. Wang Sufang, Li Xuezhi, Jiang Hua.Study on the interception of precipitation in different vegetation canopies in the rocky mountainous area of Taihang
Mountain[J]. Statistics \& Management,2015,03.

3. $\mathrm{Hu}$ Wei, Yu Jingjie, Yan Leilei. Experimental study on soil water infiltration characteristics under different land use patterns in Chongling Watershed [C] Water System and Water Resources Sustainable Management - Proceedings of the 7th China Water Forum, 2009.

4. Liu Weiqi. Study on hydrological and ecological functions of different types of bamboo forests in northern Fujian []. Ph.D thesis, Chinese Academy of Forestry, 2011.

5. Wang Peng, Song Xianfang, Hou Shibin.Study on the Influence of Typical Vegetation on Soil Water Potential Dynamics in Taihang Mountain Area[J].Journal of Natural Resources,2009,08. 